\title{
Molecular docking-simulation edge assessment of potential and less-toxic 'anti- HIV-drug and phyto- flavonoid' combination against COVID-19
}

Shasank S. Swain ( $\nabla$ swain.shasanksekhar86@gmail.com )

Division of Microbiology \& NCDs, ICMR-Regional Medical Research Centre, Bhubaneswar- 751023, Odisha, India

Satya R. Singh

Centre for Bioinformatics, Pondicherry University, Puducherry-605014, India c Department of Skin \& VD, Institute of Medical Sciences \& SUM Hospital, Siksh

\section{Alaka Sahoo}

Department of Skin \& VD, Institute of Medical Sciences \& SUM Hospital, Siksha 'O' Anusandhan Deemed to be University, Bhubenswar-751003, Odisha, India

\section{Tahziba Hussain}

Division of Microbiology \& NCDs, ICMR-Regional Medical Research Centre, Bhubaneswar- 751023, Odisha, India

\section{Sanghamitra Pati}

Division of Public Health \& Research, ICMR-Regional Medical Research Centre, Bhubaneswar-751023, Odisha, India

\section{Research Article}

Keywords: Severe Acute Respiratory Syndrome Corona Virus-2, SARS-CoV-2-Mpro, Anti-HIV- drug-phytoflavonoid combination, Molecular docking-simulation

Posted Date: May 11th, 2020

DOI: https://doi.org/10.21203/rs.3.rs-28225/v1

License: (c) (i) This work is licensed under a Creative Commons Attribution 4.0 International License. Read Full License 


\section{Abstract}

The emergence of the pandemic coronavirus-2019 (COVID-19) disease by the Severe Acute Respiratory Syndrome Corona Virus-2 (SARS-CoV-2) or 2019-novel coronavirus-2019 (2019- nCoV-2019) has created a disease-ridden environment for the entire human community, globally. However, no potent prophylactic therapy is available to control the deadly emerged viral disease. Repurposing of existing antiviral, antiinflammatory, antimalarial drugs is the only option against SARS-CoV-2. But without any clinical evidence, the recommended dose and expected side effects are under debate. As an alternative solution, we proposed a newer hypothesis using the selective, potent anti-HIV drugs and flavonoid class of phytochemicals in combination to balance the potency and toxicity during combat against SARS-CoV-2. Primarily, ten anti-HIV protease inhibitor drugs with ten phyto-flavonoids are selected as ligands for docking study against the putative target, the main protease ( $\mathrm{M}^{\mathrm{pro}}$ ) of SARS-CoV-2 (PDB ID: 6Y2E), as an essential enzyme in viral genome replication. According to molecular docking and drug-ability scores of each ligand, the anti-HIV drug, the darunavir (with a docking score, $-10.25 \mathrm{kcal} / \mathrm{mol}$ and drug-likeness rating, 0.60 ) and the quercetin-3-rhamnoside (with a docking score, $-10.90 \mathrm{kcal} / \mathrm{mol}$ and drug-likeness rating, 0.82), were selected for further analysis in the mixture. Later, the interchanged mutual docking analysis suggested that 'darunavir-quercetin-3- rhamnoside' was the most potent and less toxic drug chemical-cocktail/ formulation against SARS-CoV-2-M ${ }^{\text {pro }}$. Additionally, molecular dynamics simulation, predicted toxicity and pharmacokinetics profiles also support to the hypothesized formulation; mainly, eight strong $\mathrm{H}$ - bond interactions were found against SARS-CoV-2-M ${ }^{\text {pro }}$. Thus, projected molecular docking- simulation based active and lesser toxic 'anti-HIV-drug-phyto-flavonoid' therapy could be promoted against SARS-CoV-2.

\section{Introduction}

The pandemic of coronavirus-2019 (COVID-19) disease from the Severe Acute Respiratory Syndrome Corona Virus-2 (SARS-CoV-2) or 2019-novel coronavirus-2019 (2019-nCoV) has created a horrific situation and extremely impact of global primary health care management ${ }^{1-4}$. As per the expert, the outbreak and quick transmission of the COVID-19 is close to the severe pandemic Spanish flu that happened in 1918-19. Concomitantly, approximately $78 \%$ of SARS- CoV-2 infected patients were found in an asymptomatic manner ${ }^{5,6}$. Thus, recognition of a SARS-CoV-2 infected patient is a challenge to break the invisible transmission of the pandemic state. As per updated information, severe pneumonia, multi-organ dysfunction have been associated with a higher rate of mortality from SARS-CoV-2 in age groups of the population in different geographical regions ${ }^{7-9}$. Still, 30st April 2020, 214 countries have been suffering from the SARS-CoV-2 with 2,21,823 mortality out of 31,45,407 cases, from which maximum mortality associated with elderly-cum-health complicity community ${ }^{1}$. In India's scenario, the death per incidence is only $0.03 \%$, out of which approximately $75 \%$ mortality rate linked with the upper age-group (> 60 years) and comorbidity, as comparatively lower than the international level at present ${ }^{1}$, 10. The global situation, staring from the Republic of China to the United States of America, Italy, Spain, France, the United Kingdom, German, Spain, etc., are the most suffering countries from the deadly SARS- 
CoV-2 and at present except China, all Asian nations quite suffer less ${ }^{1,11}{ }^{1}$. Thus, it is a massive challenge for every nation-state as well as for the World Health Organization (WHO) to implement the newer emergency advisory, national health policy and therapeutic strategy to protect the entire world health system from the unknown viral disease ${ }^{1,12 .}$

According to WHO reports, several drug and vaccine candidates are under testing and still no US-Food and the Drug Administration (FDA) recommended drug is available for the treatment of the deadly disease ${ }^{13-15}$. However, fighting against the aggressive positive-sense single-strand RNA or (+)ssRNA viral infection without any compelling medicine is the most substantial fear towards the protection of the emergency health system ${ }^{15}$. Indeed, experts or physicians used several alternative combinations of existing antiviral and antiinflammatory drugs on a non-random trial or hit-and-trial basis to tackle the situation 16, 17. Mainly, existing FDA approved antiviral drugs such as baloxavir marboxil, darunavir, favipiravir, lopinavir, oseltamivir, remdesivir, ritonavir, etc., along with several immune-modulatory, antiinflammatory medications such as fingolimod, sarilumab, and tocilizumab are using in non-clinical trial repurposing and drug-combination method ${ }^{16,17}$. Even the combinatorial treatment with the obsolete antimalarial and anthracitic drug, hydroxychloroquine (Plaquenil) with the macrolide class of antibiotics azithromycin for standard flue gives an alternative solution form the clinical evidence against SARSCoV-2 ${ }^{18}$. Fortunately, strategically applied drug combinations seem good towards control of SARS-CoV2 from several obtained results, but it has different results on a geographical along with patient to patient basis ${ }^{15-18}$. From the vaccination point of view at present, eight vaccine candidates are in clinical trials and another hundred candidates in the preclinical trial stage. However, as per the expert source, it needs a minimum of one year for validation and marketing of a potent SARS-CoV-2 vaccine.

On the other hand, several alternative non-targeting treatment therapies and regimens such as Nitric Oxide (NO) inhalation, human Natural Killer (NK) cells, or innate lymphocytes, humanized monoclonal antibody (mAb) based formulation and several active traditional regiments under clinical validation according to FDA guidelines ${ }^{19-21}$. Currently, the anti-HIV medicine, darunavir, remdesivir, lopinavir, ritonavir are the most working prophylactic agents against SARS-CoV-2 in repurposing basis in different combinations and doses 15,22 . Therefore, we cannot switch off the drug combinations ordinarily until available of any substituted potential drug/ vaccine. However, the non-standardized recommended drug combinations without any clinical evidence create severe side effects ${ }^{23-25}$. Thus, the development/ formulation of well- tolerated with lesser side treatment therapies/ regimens is the call of the day.

As an alternative solution, using screened-out any antioxidants, antiinflammatory and antiviral phytochemical(s) with an anti-HIV/ antiviral medicines than used double anti-HIV/ antiviral or any mainstream drug combinations, is expected to control the post-treatment side effects as well enhance the activity. From Indian ancient Ayurvedic and Traditional Chinese Medicine (TMC), several natural products/ regimens have been active against viral diseases ${ }^{26-29}$. Recently, the activity of such secondary metabolites against SARS-CoV-2 has been reported through several random computational and experimental studies, too, from worldwide researchers ${ }^{30-33}$. Consequently, polyphenol or flavonoids class 
of phytochemicals are well verified and reported having potential immune-stimulant and antiviral properties ${ }^{34-38}$. In parallel, some TMC regimen has already tested and shown a positive response towards the control of SARS-CoV-2. Several active TMC formulations are also under clinical validation against SARS- CoV-2 for FDA approval 20,39, 40. Herein, the present work hypothesizes smartly with selective anti-HIV drugs and phyto-flavonoids in combination to combat SARS-CoV-2, an iron hand. As per the hypothesis, an advanced, cost-effective and time-saving molecular-docking-simulation approach was used to evaluate the biological activity, toxicity and drug-ability of the combination formula. Herein, the recently submitted crystallographic structure of the main proteinase $\left(\mathrm{M}^{\mathrm{pro}}\right)$ used as a drug target during the validation. Mainly, the viral protease is a prudent drug target, as the $\mathrm{M}^{\text {pro }}$ plays a pivotal enzyme for viral genome replication 30,32,39, 40. Thus, this might be a novel idea in current anti-CoV drug development by utilizing the potent natural product along with an anti-HIV drug feasibly and costeffectively.

\section{Materials And Methods}

Preparation of ligand and target structure for computational analyses. Based on previous ethnomedicinal evidence, literature, and drug bank information, the chemical structure of ten anti-HIV protease inhibitor drugs and ten flavonoid class of phytochemicals were selected for use in drug-combination approach against SARS-CoV-2-M ${ }^{\text {pro }}$. The anti-HIV drugs, amprenavir, ASC09 (TMC310911), atazanavir, darunavir, indinavir, lopinavir, nelfinavir, ritonavir, saquinavir, tipran avir and the phyto-flavonoids, apigenin, catechin, dihydroquercetin, epigallocatechin gallate, hesperidin, hesperidin, LPRP-Et-97543, quercetin, quercetin-3rhamnoside and rutin were retrieved as ligands from PubChem database (https://pubchem.ncbi.nlm.nih.gov/). Further, the recently submitted three-dimensional crystal structure of the SARS-CoV-2-Mpro enzyme bearing 306 amino acids as a target protein, was extracted from protein data bank (PDB) with an ID: 6Y2E for use in the docking-simulation study towards the selection of most active drug-able compound. Additionally, both structure- and sequence-level analyses were carried out between the SARS-CoV-2-M ${ }^{\text {pro }}$ with previously reported crystal structure of SARS-CoV-M ${ }^{\text {pro }}$ (PDB ID: 2DUC) with the protein fold recognition server, Phyre2 (http://www.sbg.bio.ic.ac.uk/phyre2/).

Molecular docking of both drug and phytochemicals. The present computational work was carried out in Linux-Ubuntu 16.04 LTS workstation. The software namely, AutoDock 4.1 for both single and double docking study and the BIOVIA Discovery Studio (BIOVIA DSB v4.5) for visualization of the target-ligand interactions during docking . Retrieved target structure of SARS-CoV-2-Mpro and each ligand were saved in $\operatorname{dot}($.$) pdb format before docking study 41,42$. Additionally, first energy minimization of the retrieved SARS-CoV-2-M ${ }^{\text {pro }}$ was carried out through simulation at 50 nano second (ns) before docking. The default sets of docking parameters of AutoDock tools, as Kollman charges with polar hydrogen bonds for target, while Geister partial charges for ligands were used. The grid size 126x126x126 during proteinligand and 40x40x40 during ligand-ligand docking was used. Particularly, interchanged double docking study between selected two phyto-flavonoids, quercetin-3-rhamnoside and LPRP-Et-97543, with the

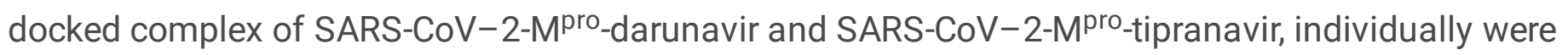


performed. Additionally, interchange ligand-ligand docking between darunavir-quercetin-3-rhamnoside, darunavir-LPRP-Et-97543, tipranavir-quercetin-3- rhamnoside and tipranavir-LPRP-Et-97543 were performed ${ }^{42}$, 43. Generated ten interaction poses for each ligand, the most effective pose was selected based on its binding energy/ docking score and ligand efficacy ${ }^{41-43 . ~ F u r t h e r, ~ t h e ~ m o s t ~ e f f e c t i v e ~ d o c k i n g ~}$ complexes were selected for stability check by molecular dynamic simulation (MDS) study.

Molecular dynamic simulation study with most effective protein-ligand complexes. Further, the native/ apo-enzyme protein structure, most effective protein-drug, protein-phyto and protein- drug-phyto docking complexes were selected for molecular dynamic simulation (MDS) study to check the stability pattern of each docking complexes in an appropriate computational environment. A total of $50 \mathrm{~ns}$ for apo-enzyme and 30 ns MDS for each docking complexes with GROMACS (Groningen Machine for Chemical Simulations) package (version 5.1.4) with GROMOS force field was carried out ${ }^{42}$. Parameters and topologies files for each complex were generated using the PRODRG server. Native protein and selected three most effective docking complexes with the SPCE water-cubic box model (whose volume was about $976.40,976.50,977.48,977.48 \mathrm{~nm} 3$, respectively) were simulated. A total of $30576,30564,30573$ and 30563 numbers of solvent molecules added to each system from native protein structure to double docking complexes. Neutralized the system by adding $4 \mathrm{Na}+$ ions, as well as the energy minimization using 50,000 steepest descent steps, was carried out for each docking complex. After minimization of the system, the NVT (number of particles, volume and temperature) and NPT (number of particles, pressure, temperature) equilibrations were performed for equilibrating the system for the 100ps time scale for each. The final MD step was performed for the protein system for a $30 \mathrm{~ns}$ time scale and with time steps of $2 \mathrm{fs}$ 42.

Possible toxicity and drug-ability prediction for both anti-HIV drug and phytochemicals. The primary toxicity profiles of both anti-HIV drugs and phyto-flavonoids using the generated simplified molecularinput line-entry system (SMILES) code for each chemical structure, was investigated. The toxicity profiles such as hepatotoxicity, carcinogenicity, immunotoxicity toxicity, mutagenicity, cytotoxicity, along with toxicity class and possible lethal dose $\left(\mathrm{LD}_{50}\right)$ value using the tool, ProTox (http://tox.charite.de/protox_II/), was recorded. Additionally, the overall drug-likeness or possibility for a drug, based on the chemical composition of each ligand was measured using the tool, Molsoft (http://molsoft.com/mprop/).

Possible pharmaceutical profiles prediction for both anti-HIV drug and phytochemicals. Besides the crucial drug-selection parameter, pharmacokinetics profiles as known as, Absorption, Distribution, Metabolism, Excretion, and Toxicity (ADME/T) properties of used anti-HIV drugs and phyto-flavonoids were assessed using the tool, SwissADME (http://www.swissadme.ch/).

\section{Results}

Preparation of ligand and target structure for computational analyses. The selected chemical structure of anti-HIV protease inhibitor drugs and phyto-flavonoids with individual PubChem with physicochemical 
properties such as molecular weight $(\mathrm{g} / \mathrm{mol})$, number of H-bond acceptors, $\mathrm{H}$-bond donors, octanol/ water partition coefficient (XlogP), topological polar surface area (tPSA in $\AA$ ), molar refractivity ( $\mathrm{mol} / \mathrm{m} 3)$, number of rotatable bonds were recorded (Table S1 \& Table S2).. Currently, all cited parameters are collectively known as the Lipinski rule five (RO5) in the current drug development module. However, all drugs do not follow the standard R05 regulations, while a maximum number of phyto-flavonoids are obeying the R05 rules. Currently, the R05 is a fundamental physicochemical parameter based standard rule to filter the possible drug-able compound in the early stage of 'lead drug' selection. On the other hand, from fold recognition analysis with the selected target SARS-CoV-2-Mpro (ID: 6Y2E) confirmed that a >92 $\%$ structural portion with previously recognized SARS-CoV-M ${ }^{\text {pro }}$ (2DUC) was conserved (Fig. 1).. Concomitantly, from sequence-level analysis, twelve substituted amino acids/ mutations also found. From which nine variations/ mutations were conservative in between both CoV-M ${ }^{\text {pro }}$. Thus, the pandemic SARS-CoV-2-M ${ }^{\text {pro }}$ is structurally-sequentially conserved, but the mutated amino acids may be associated with the development of severity or resistance to applied treatments.

Molecular docking of both drug and phytochemicals. The molecular docking score of selected 20 ligands (ten anti-HIV protease inhibitors drugs or $n=10$ and ten phyto-flavonoids or $n=10$ ) against the energy minimized and a stable (in 50 ns MDS) allosteric target, SARS-CoV-2- M $^{\text {pro }}$ was recorded (Table 1 \& Table 2; Figs. S1 to S3).. Among all anti-HIV drugs, darunavir with docking score, $-10.25 \mathrm{kcal} / \mathrm{mol}$ and tipranavir with docking score, $-10.14 \mathrm{kcal} / \mathrm{mol}$ were two most potent drugs against SARS-CoV-2-Mpro, based on recorded docking score (Table 1).. Similarly, from the phyto-flavonoid side, quercetin-3rhamnoside with docking score, $-10.90 \mathrm{kcal} / \mathrm{mol}$ and LPRP-Et-97543 with docking score, -10.11 $\mathrm{kcal} / \mathrm{mol}$ were recorded (Table 2).. From molecular interactions study, the potent antiviral drug darunavir has formed three hydrogen bond interactions with amino acids with LYS5 and LEU282 (Fig. 2).. In comparison, quercetin-3- rhamnoside has assembled eight potent $\mathrm{H}$-bond interactions at amino acids, LYS5, ALA7, GLN127, LYS137 and GLU290 (Fig. 3),, respectively against SARS-CoV-2-M ${ }^{\text {pro }}$ during docking study. Herein confirmed that the phyto-flavonoid quercetin-3-rhamnoside was more potent and stable than anti-HIV drugs in molecular docking analysis. As per the hypothesis of the combination drug approach, a total of four candidates $(n=4)$, from which two potent anti-HIV drugs, darunavir and tipranavir $(n=2)$ and LPRP-Et-97543 and quercetin-3-rhamnoside $(n=2)$, were selected. Hypothetically, the double-docking score is comparatively higher than the individual docking score of each selected ligands. Fortunately, among four double-docking complexes, the darunavir-quercetin-3-rhamnoside $(\mathrm{n}=$ 1) combination was the most effective combination with total docking score, -14.83 (double docking score, $-10.95 \mathrm{kcal} / \mathrm{mol}$ and ligand- ligand docking score, $-3.88 \mathrm{kcal} / \mathrm{mol}$ ) than other double docking complexes (Table 3; Fig. 4).. Above all docking analysis, three docking complexes, SARS-CoV-2-Mpro_

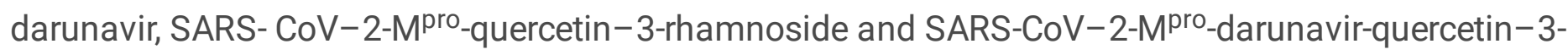
rhamnoside were selected for stability analyses with MDS at $30 \mathrm{~ns}$.

Molecular dynamic simulation study with most effective protein-ligand complexes. Towards understand the structural stability of native protein with selected protein-ligand docking complexes through the root mean square deviation (RMSD)-protein backbone, root mean square fluctuation (RMSF)-C-alpha and 
Radius of gyration $(\mathrm{Rg})$ of protein were analyzed by MDS. The explained RMSD plot of single protein determined that continuous unorthodoxy in backbone protein has appeared during $50 \mathrm{~ns}$ time. But between 32 to $46 \mathrm{~ns}$, absolute mere stability was found from the analyzed plot (Fig. S1).. Similarly, the RMSF-plot describes the c-alpha and Rg- plot of the whole protein including c-alpha, backbone and sidechain described the inconsistency to maintain the stability during $50 \mathrm{~ns}$ in extracted plots (Figs. S2 \& S3).

From the single docking complex of SARS-CoV-2-Mpro-darunavir, SARS-CoV-2-Mpro- quercetin-3rhamnoside, the RMSD plot of quercetin-3-rhamnoside was comparatively more stable than the darunavir complex (Fig. 5).. Protein backbone of SARS-CoV-2-Mpro-quercetin-3- rhamnoside (green color bar in Fig. 5), showing the least deviation in between 0 to $29 \mathrm{~ns}$, while SARS-CoV-2-Mpro-darunavir (blue color bar in Fig. 5) displayed the variation for first 20 ns and the rest 10 ns gradually less fluctuate in plotted RMSD. Similarly, the RMSD plot of double docking was comparative higher fluctuation at an upper length, $>0.25 \mathrm{~nm}$ between 10 to $15 \mathrm{~ns}$ (orange color bar in Fig. 5). From the above RMSD plot analysis, quercetin-3-rhamnoside having the least fluctuation within $30 \mathrm{~ns}$ (Fig. 5).. Correspondingly, garnered individual RMSF- and Rg- plots of and overplayed for judgment the variation with simulation time in between three docking complexes (Figs. 6 \& 7).. Based on the RMSF-analyses, both anti-HIV drug

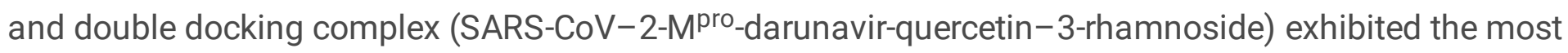
diverged value in corresponding to $\mathrm{C}$-alpha residues than phyto-flavonoids. Furthermore, Rg-plots showed the compactness or solidity of the quercetin-3-rhamnoside with more squeezed Rg-values rather than other complexes (Fig. 7).. Additionally, $\mathrm{H}$-bond interaction analyses exposed that, eight strong $\mathrm{H}$-bond interactions in both SARS-CoV-2-Mpro-quercetin-3-rhamnoside (green color bar in Fig. 8) and SARSCoV-2-Mpro-darunavir-quercetin-3-rhamnoside (in the orange color bar), were found (Fig. 8).. In the form of activity based on strong $\mathrm{H}$-bond interactions points of view, the quercetin-3-rhamnoside was a most active component than the anti-HIV drug darunavir; as a result, the flavonoid combined drug formulation exhibited the most therapeutic potency towards inhibition of SARS-CoV-2.

Possible toxicity and drug-ability prediction for both anti-HIV drug and phytochemicals. The toxicity or side effect is a significant concern for implementation of therapeutic agents/ drugs. Currently, a maximum number of lead-drug candidates unable to express the ideal safety pieces of stuff and later on, withdrawn from the clinical trial. Herein, from the predicted toxicity profile records, phyto-flavonoids were comparatively safer than the anti-HIV drugs (Tables 4 \& 5).. However, except for hepatotoxicity and immunotoxicity, anti-HIV drugs are safer like phytochemicals. Mainly selected darunavir showed a moderately reliable under class-III category with severe hepatotoxicity (Table 4).. On the other hand, phyto-flavonoid, the quercetin-3- rhamnoside, was reasonably safer with class-V, as a more reliable/ inoffensive drug-able compound (Table 5)..

In the same way, the overall drug-likeness or possibility for a drug molecule score for each ligand was recorded (Tables $1 \& 2$ ).. As per the drug-ability plot, positive drug-likeness value is good; a score between 0.60 to 1.20 is an ideal score to be a successive drug molecule. The drug candidates presented perfect drug-likeness scores, while it was discernible that all phyto-flavonoids too exhibited drug-like scores as a 
recommended anti-HIV drugs, computationally. The drug-ability score of the quercetin-3-rhamnoside had the most potential score, 0.82 , while the anti-HIV drug darunavir score, 0.60 (Figs. S4 \& S5). Thus, as per the predicted drug-likeness score, it also supported the proposed phyto-drug combination.

Possible pharmaceutical profiles prediction for both anti-HIV drug and phytochemicals. At the close stage of drug validation, the pharmacokinetics profile plays a crucial during recommendation. Moreover, advanced computational tools also able to provide some statistical-based reports for each ligand from its training set documents at an early stage. Herein, both anti- HIV drugs and phyto-flavonoids pharmacokinetics profiles were recorded (Tables S3 \& S4).. As per reports, except for lopinavir and indinavir, rest for anti-HIV medicines have lower gastrointestinal absorption (GI-abs.), including darunavir (Table S3).. Similarly, all drugs are unable to cross the blood-brain barrier (BBB) report. On the other hand, pharmacokinetics profiles of phyto-flavonoids displayed in a changeability manner of Gl-abs., P-gp substrate, etc., where the quercetin-3-rhamnoside was similar to anti-HIV drug profile along with, all phytochemical showed the same negative BBB cross report. (Table S4).. The overall pharmacokinetics also reports of all ligands were presented, graphical (Figs. S6 \& S7).. From the above analysis reports, all ligands are some deviate profiles, mainly phytochemicals. As a result, a combination of a mainstream drug with a phytochemical may have maintained the activity as well as pharmacokinetics in the presence of one with another during treatment.

\section{Discussion}

Since the last decade, a continuous outbreak staring from Dengue, Nipah, Ebola, Chikungunya, Zika and currently the SARS-CoV-2, an updated version of Middle East Respiratory Syndrome (MERS) and Severe Respiratory Syndrome (SARS) CoV family, threatening the human health and economy ${ }^{1-4}$. Like an upgraded version of drug/ antibiotics, the virus also reconstructed their genome through genetic or environmental pressure; as a result, the omnipotent human unable to protect from the massive storm of deadly viral infection $3,4,7,8$. Motionless, the origin of SARS- CoV-2 is under investigation, but it is continuing the unpredictable morbidity and mortality rates in wildfire gestures without any differentiation between age group, gender, race, poor, rich and geographical region ${ }^{3,8}$. However, the actual activities, route of transmission and especially symptoms of SARS-CoV-2 infection are still indistinguishable. Notably, the genomic information of SARS-CoV-2 is quite diversified from the previously isolated strain of the Co-V family; as a result, several newer serotypes continuously isolated from several geographic regions $7,8,44,45$. Someway the more updated genomic material, clinical evidence and epidemiology analysis stretch some clues in the scientific community to applying some novel strategy as well as towards developing some therapeutic regimen towards control of the SARS- CoV-2 ${ }^{44-46 .}$

Currently, no FDA-recommended drug/ vaccine is available for the treatment of the SARS-CoV-2; somehow, several alternative combinations of existing antiviral, antiinflammatory, antimalarial drugs in a

hit-and-trial basis ${ }^{15-19}$. Mainly, as from the experience of previously used combinations for MERS- and SARS-Co-V virus were more viable, as members of similar taxa with a higher genomic match ${ }^{44,46}$. The 
anti-HIV drugs, ASC09, darunavir, lopinavir, ritonavir as potent viral protease inhibitors, oseltamivir, a potent anti-H1N1 neuraminidase inhibitor, favipiravir and umifenovir as potent anti-influenza drugs targeting viral RNA-dependent RNA polymerase, anti-ebola drug, remdesivir targeting viral RNA polymerase, are most widely used drugs in repurposing basis with several combinations ${ }^{15,22}$. However, the multi-drug combinations are complicated in SARS-CoV-2 patients with multiple comorbidities such as diabetics, hypertension, respiratory disease and cardiac dysfunctions $24,25,47,48$. From the vaccination point of view, it needs a minimum of one year for validation and marketing of a budding vaccine candidate against SARS-CoV-2 with FDA recommendation ${ }^{14,17}$.

Alternatively, several non-target conventional treatment therapies with natural regimens/ products are quite a classic area for any infectious diseases 39, 49, 50. Ordinarily, phytochemicals have been suggested as a vibrant conservative resource, since individual plant crude extracts and isolated secondary metabolites curative potential against various health ailments $35,45,50$. Natural plant products such as curcumin, quinine, taxol, vincristine, morphine, etc., have been playing a significant role in the contribution of several mainstream medicines 49 , 50. From the structural point of view, the flavonoid or polyphenol class of phytochemicals is more suitable and safer secondary metabolites for human administration with potent immune-stimulant and antioxidant as a lesser toxic/ non-toxic class of drug candidates 35-39, 51. For example, the flavonoid class of derivatives, phenoxodiol, genistein and polyphenolic constituents from green tea and soybeans are now in a different stage of clinical trials as a potent anticancer regimen 52. Someway, non- conventional therapy using Ayurveda and TCM regimens gives some productive outputs against SARS-CoV-2 from several recent reports $26,27,28,29$.

Concomitantly, the computer-aided drug development (CADD) program is a cost- effective and time saving and decisive method in ongoing drug discovery modules. The CADD program could be a promising endeavor in newer anti-CoV drug development using lead-drug candidates than the traditional hit-and-trial selection process ${ }^{30-33 .}$ Mainly, the high-throughput screening to locate active most chemical moieties based on binding energy or docking scores before synthesis and expensive experimental validation are directly influencing the reduction of cost of medicine in the later stage $42,53,54$. Furthermore, the backbone RMSDs, Ca-RMSF, Rg- plot, and intermolecular H-bonds analyses through allatom MDS provide more productive results with more thermodynamic features as well as, underlying kinetics behavior of protein- ligand docking complexes $42,53,54$. Notably, MDS suggests that SARS-CoV-

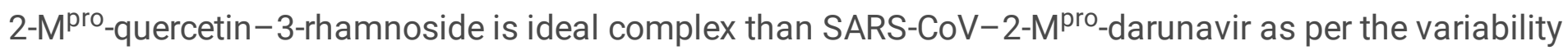
observation within $30 \mathrm{~ns}$. Additionally, the combination of darunavir-quercetin-3-rhamnoside makes strong interactions against SARS-CoV-2-Mpro from $\mathrm{H}$-bond analysis. MDS for an extended period with these complexes may share more high-volume results on stability or structural flexibility in different time intervals. Subsequently, computational tools can predict the possible toxicity and drug-ability profile of a chemical; as a result, ordinarily remove the unwanted/ toxic chemicals in the preclinical stage 53,54 . Thus, combined with a potent anti-HIV protease inhibitor drug is the most excellent and inspiring approach for 
the utilization of more phytochemicals in mainstream medicine during searching for alternative therapy against SARS-CoV-2 at emergency.

\section{Conclusion}

Currently, the entire global health system in the intensive care unit (ICU) and the whole community living under insecurity from the pandemic of SARS-CoV-2. Without any clinical evidence, the repurposing of existing antiviral, antiinflammatory, antimalarial, etc., medicines is the only therapeutic option against SARS-CoV-2. However, clinical dose and a proper assessment of post-treatment side effects of ongoing repurposing drug therapies are an essential guideline-cum-challenge for any physician/ clinician, as treatment has linked with severe side effects/ host-toxicity from recent clinical reports. As an alternative solution, we proposed a newer hypothesis using potent anti-HIV protease inhibitor drugs with an active flavonoid class of phytochemicals towards balancing the toxicity and potential effects to combat SARSCoV-2. Moreover, flavonoids reported as a potent antioxidant, antiinflammatory, immune-stimulant with potent antiviral activities with non-toxic/ lesser toxic actions. Among ten anti-HIV-drugs with ten phyto flavonoids, darunavir and quercetin-3-rhamnoside were selected as the most potent SARS-CoV-2-M ${ }^{\text {pro }}$, at primary analyses. Future based on advanced molecular docking-simulation, overall drug-likeness score, toxicity and pharmacokinetic profiles study, the 'darunavir-quercetin-3-rhamnoside' was the most effective and less toxic pharmacological active mishmash against SARS-CoV-2-M ${ }^{\text {pro }}$. Thus, the proposed 'anti-HIV-drug-phyto-flavonoid' combination could be promoted against SARS-CoV-2 as a potent natural-based antiviral therapy with lesser post-treatment adverse effects to the host. Strategically, computer-aided drug design could be a promising endeavor in newer anti-CoV drug development during possible lead-drug candidate(s) selection than the traditional hit-and-trial selection process in this challenging time.

\section{Declarations}

\section{Acknowledgements}

The "ICMR-Young Scientist Research Scheme" awarded to Shasank S. Swain (FTS No.3128113/No.R.12014/14/2017-HR) form Department of Health Research, Govt. of India, New Delhi is acknowledged. Special thanks to the Honorable Director, Indian Council of Medical Research, Govt. of India, New Delhi, the Director, Regional Medical Research Centre, Bhubaneswar for facilities and the World Health Organization for updated information on COVID-19 in this challenging time. The work is dedicated to our special heroes (Doctors, Nurses, Pharmacists, Associated Healthcare Persons, Police, Leader, Media, etc.)) for constant untiring cooperation in this pandemic situation to save us from COVID-19.

\section{Author contributions}


S.S.S., S.R.S., A.S., conceptualized the research design; S.R.S., A.S, carried out the advanced computation assessments and organized the results according to S.S.S direction; S.S.S. draft the MS and T.H, and S.P. review, analyzed and give the final touch before submission.

\section{Competing interests}

The authors declare no competing interests.

\section{References}

1. WHO-Coronavirus disease (COVID-19) pandemic. https://www.who.int/ emergencies/ diseases/novel-coronavirus-2019 (2020) (Assessed on 30 April 2020).

2. Wang, C., Horby, P.W., Hayden, F.G. \& Gao, G.F. A novel coronavirus outbreak of global health concern. Lancet, 395, 470-473 (2020).

3. Munster, V.J., Koopmans, M., van Doremalen, N., van Riel, D. \& de Wit, E. A novel coronavirus emerging in China - key questions for impact assessment. Engl. J. Med. 382, 692-694. (2020)

4. Arshad Ali, S., Baloch, M., Ahmed, N., Arshad Ali, A. \& Iqbal, A. The outbreak of coronavirus diseases 2019 (COVID-19)-An emerging global health threat. Infect. Pub. Health 13, 644-646. (2020).

5. Coronavirus: BMJ study suggests $78 \%$ don't show symptoms - here's what that could mean. https://theconversation.com/coronavirus-bmj-study-suggests-78-dont-show-symptoms-heres- whatthat-could-mean-135732. (2020) (assessed on 30 April 2020).

6. Pan, X., Chen, D., Xia, Y., Wu, X., Li, T., Ou, X., Zhou, L. \& Liu, J. Asymptomatic cases in a family cluster with SARS-CoV-2 infection. Infect. Dis. 20, 410-411 (2020).

7. Huang, C., Wang, Y., Li, X. \& et al. Clinical features of patients infected with 2019 novel coronavirus in Wuhan, China. Lancet. 395, 497-506 (2020).

8. Islam, A., Ahmed, A., Naqvi, I.H. \& Parveen, S. Emergence of deadly severe acute respiratory syndrome coronavirus-2 during 2019-2020. Virusdisease. 8, 1-9 (2020).

9. Lin, , Lu, L., Cao, W. \& Li, T. Hypothesis for potential pathogenesis of SARS-CoV- 2 infection-a review of immune changes in patients with viral pneumonia. Emerg. Microbes. Infect. 9, 727-732 (2020).

10. India Today: Coronavirus: $75 \%$ cases of deaths in patients aged $60 \mathrm{yrs}$. and above, $83 \%$ have comorbidities. https://indiatoday.in/india/story/coronavirus-india-health-ministry-pc- deaths-comorbidities-percentage-total-cases-1668391-2020-04-18 (2020) (assessed on 30 April 2020).

11. The Guardian: Coronavirus world map: which countries have the most cases and deaths? https://www.theguardiacom/world/2020/may/01/coronavirus-world-map-which-countries- have-themost-cases-and-deaths (2020). (assessed on 30 April 2020).

12. WHO-Health systems respond to COVID-19. http://www.euro.who.int/data/assets/pdf file/0006/437469/TG2-CreatingSurgeAcutelCUcapacity-eng.pdf (2020). (assessed on 30 April 2020). 
13. WHO-draft landscape of COVID-19 candidate vaccines - 23 April 2020. https://www.who. int/blueprint/priority-diseases/key-action/draft-landscape-COVID-19-candidate-vaccines-23- April2020.pdf?ua=1. (2020) (assessed on 30 April 2020).

14. Thanh Le, T., Andreadakis, Z., Kumar, A., Gómez Román, R., Tollefsen, S., Saville, M. \& Mayhew, S. The COVID-19 vaccine development landscape. Rev. Drug. Discov. (2020). doi:10.1038/d41573-02000073-5.

15. Sanders, J.M., Monogue, M.L., Jodlowski, T.Z. \& Cutrell, J.B. Pharmacologic treatments for coronavirus disease 2019 (COVID-19): A review. JAMA (2020). doi:10.1001/jama.2020. 6019.

16. Iyer, M., Jayaramayya, K., Subramaniam, M.D., Lee, S.B., Dayem, A.A., Cho, S.G. \& Vellingiri, B. COVID19: an update on diagnostic and therapeutic BMB. Rep. 53, 191-205 (2020).

17. Ahn, D.G., Shin, H.J., Kim, M.H., Lee, S., Kim, H.S., Myoung, J. et al. Current status of epidemiology, diagnosis, therapeutics, and vaccines for novel coronavirus disease 2019 (COVID-19). Microbiol. Biotechnol. 30, 313-324 (2020).

18. Gautret, P., Lagier, J.C., Parola, P., Hoang, V.T., Meddeb, L., Mailhe, M. et al. Hydroxy- chloroquine and azithromycin as a treatment of COVID-19: results of an open-label non- randomized clinical trial. J. Antimicrob. Agents. 105949 (2020). doi:10.1016/j.jjantimicag. 2020.105949.

19. Zhang, J., Xie, B. \& Hashimoto, K. Current status of potential therapeutic candidates for the COVID-19 crisis. Behav. Immun. pii:S0889-1591, 30589-4 (2020).

20. US-National Library of Medicine: ClinicalTrials.gov. https://clinicaltrials.gov/. (assessed on 30 April 2020).

21. Lu, R.M., Hwang, Y.C., Liu, I.J., Lee, C.C., Tsai, H.Z., Li, H.J. \& Wu, H.C. Development of therapeutic antibodies for the treatment of diseases. Biomed. Sci. 27, 1 (2020). doi:10.1186/ s12929-019-0592-z.

22. Harrison, C. Coronavirus puts drug repurposing on the fast track. Biotechnol. 38, 379- 381 (2020).

23. FitzGerald, G.A. Misguided drug advice for CIVID-19. Science. 367, 1434 (2020). doi:10.1126/science.abb8034.

24. Jaffe, S. Regulators split on antimalarials for COVID-19. Lancet. 395, 1179 (2020). doi:10.1016/S0140-6736(20)30817-5.

25. Science: Antimalarials widely used against COVID-19 heighten risk of cardiac arrest. How can doctors minimize the danger?. https://www.scienceorg/news/2020/04/ antimalarials- widely-usedagainst-covid-19-heighten-risk-cardiac-arrest-how-can-doctors. (2020) (assessed on 30 April 2020).

26. Rege, A.A. \& Chowdhary, A.S. Evaluation of some medicinal plants as putative HIV-protease inhibitors. Indian Drugs. 50, 24-28 (2013).

27. Rastogi, S., Pandey, D.N. \& Singh, R.H. COVID-19 Pandemic: A pragmatic plan for Ayurveda intervention. Ayurveda. Integr. (2020) doi:10.1016/j.jaim.2020.04.002

28. Luo, E., Zhang, D., Luo, H., Liu, B., Zhao, K., Zhao, Y. et al. Treatment efficacy analysis of traditional Chinese medicine for novel coronavirus pneumonia (COVID-19): an empirical study from Wuhan, Hubei province, China. Med. 15, 34 (2020). doi:10.1186/s13020- 020-00317-x. 
29. Yang, , Islam, M.S., Wang, J., Li, Y. \& Chen, X. Traditional Chinese Medicine in the treatment of patients infected with 2019-new coronavirus (SARS-CoV-2):A review and perspective. Int. J. Biol. Sci. 16, 1708-1717 (2020).

30. Islam Parves, R., Paul, A.S., Uddin, N., Rahman, M.S., Mamun, A.A. et al. A molecular modeling approach to identify effective antiviral phytochemicals against the main protease of SARS-CoV-2. Biomol. Struct. Dyn. 1-20. (2020) doi:10.1080/07391102.2020.1761883.

31. Ul Qamar, M.T., Alqahtani, S.M., Alamri, M.A. \& Chen, L.L. Structural basis of SARS- CoV-2 3CL ${ }^{\text {pro }}$ and anti-COVID-19 drug discovery from medicinal plants. Pharm. Anal. (2020).

doi:10.1016/j.jpha.2020.03.009.

32. Wang, Fast identification of possible drug treatment of coronavirus disease -19 (COVID-19) through computational drug repurposing study. J. Chem. Inf. Model. (2020). doi:10.1021/acs. jcim.0c00179.

33. Aanouz, I., Belhassan, A., El Khatabi, K., Lakhlifi, T., El Idrissi, M. \& Bouachrine, M. Moroccan medicinal plants as inhibitors of COVID-19: Computational investigations. Biomol. Struct. Dyn. 1-12 (2020). doi:10.1080/07391102.2020.1758790.

34. Choi, H.J., Song, J.H. \& Kwon, H. Quercetin-3-rhamnoside exerts antiinfluenza-A virus activity in mice. Phytother. Res. 26, 462-464 (2012).

35. Huang, T.J., Tsai, Y.C., Chiang, S.Y., Wang, G.J., Kuo, Y.C., Chang, Y.C. \& Wu, Y.Y. Anti-viral effect of a compound isolated from Liriope platyphylla against hepatitis B virus in vitro. Virus Res. 192, 16-24 (2014).

36. Pasetto, S., Pardi, V. \& Murata, M. Anti-HIV-1 activity of flavonoid myricetin on HIV- 1 infection in a dual-chamber in vitro model. PLoS One. 9, e115323 (2014). doi:10.1371/ journal.pone.0115323.

37. Ortega, J.T., Serrano, M.L., Suárez, A.I., Baptista, J., Pujol, F.H., Cavallaro, L.V. et al. Antiviral activity of flavonoids present in aerial parts of Marcetia taxifolia against hepatitis B virus, poliovirus, and herpes simplex virus in vitro. EXCLI J. 18, 1037-1048 (2019).

38. Lalani, S. \& Poh, C.L. Flavonoids as antiviral agents for Enterovirus A71 (EV-A71). Viruses 12, pii:E184 (2020) doi:10.3390/v12020184.

39. Gentile, D., Patamia, V., Scala, A., Sciortino, M.T., Piperno, A. \& Rescifina, A. Putative inhibitors of SARS-CoV-2 main protease from a library of marine natural products: A virtual screening and molecular modeling study. Drugs. 18, pii:E225 (2020). doi:10.3390/ md18040225.

40. Jin, Z., Du, X., Xu, Y., Deng, Y., Liu, M., Zhao, Y. et al. Structure of $\mathrm{M}^{\text {pro }}$ from COVID- 19 virus and discovery of its inhibitors. Nature (2020). doi:10.1038/s41586-020-2223-y.

41. Swain, S.S., Paidesetty, S.K. \& Padhy, R.N. Development of antibacterial conjugates using sulfamethoxazole with monocyclic terpenes: A systematic medicinal chemistry based computational approach. Computer Method. Program. Biomed. 140, 185-194 (2017).

42. Swain, S.S., Paidesetty, S.K., Dehury, B., Das, M., Chaitanya, S.V. \& Padhy, R.N. Computer-aided synthesis of dapsone-phytochemical conjugates against dapsone-resistant Mycobacterium leprae. Rep. s41598-020-63913-9 (2020). 
43. Mishra, , Paital, B., Jena, S., Swain, S.S., Kumar, S., Yadav, M.K., Samanta, L. \& Chainy, Possible activation of NRF2 by Vitamin E/ Curcumin against altered thyroid hormone induced oxidative stress via NFKB/AKT/ mTOR/ KEAP1 signalling in rat heart. Sci. Rep. 9, 7408. s41598-019-43320-5. (2019).

44. Lu, R., Zhao, X., Li, J., Niu, P., Yang, B., Wu, H. et al. Genomic characterization and epidemiology of 2019 novel coronavirus: implications for virus origins and receptor binding. Lancet 395, 565-574 (2020).

45. Wang, H., Li, X., Li, T., Zhang, S., Wang, L., Wu, X. \& Liu, J. The genetic sequence, origin, and diagnosis of SARS-CoV. J. Clin. Microbiol. Infect. Dis. (2020). doi:10.1007/s10096-020-03899-4.

46. Wang, Q., Zhang, Y., Wu, L., Niu, S., Song, C. \& Zhang, Z. Structural and functional basis of SARS-CoV2 entry by using human ACE2. Cell pii:S0092-8674(20)30338-X (2020).

doi:10.1016/j.cell.2020.03.045.

47. Yang, J., Zheng, Y., Gou, X., Pu, K., Chen, Z., Guo, Q. et al. Prevalence of comorbidities and its effects in coronavirus disease 2019 patients: A systematic review and meta-analysis. J. Infect. Dis. 94, 9195(2020). doi:10.1016/j.ijid.2020.03.017.

48. Emami, A., Javanmardi, F., Pirbonyeh, N. \& Akbari, Prevalence of underlying diseases in hospitalized patients with covid-19: a systematic review and meta-analysis. Arch. Acad. Emerg. Med. 8, e35 (2020).

49. Newman, D.J. \& Cragg, G.M. Natural products as sources of new drugs over the nearly four decades from 01/1981 to 09/2019. Nat. Prod. 83, 770-803 (2020).

50. Swain, S.S., Paidesetty, S.K., Padhy, R.N. \& Hussain T. Isoniazid-phytochemical conjugation: A new approach for potent and less toxic anti-TB drug Chem. Biol. Drug. Des. 1-17 (2020). https://doi.org/10.1111/cbdd.13685.

51. Tungmunnithum, D., Thongboonyou, A., Pholboon, A. \& Yangsabai, A. Flavonoids and other phenolic compounds from medicinal plants for pharmaceutical and medical aspects: An overview. Medicines (Basel) 5, pii:E93 (2018). doi:10.3390/medicines5030093.

52. Russo, M., Spagnuolo, C., Tedesco, I. \& Russo, G.L. Phytochemicals in cancer prevention and therapy: truth or dare?, Toxins (Basel) 2, 517-551 (2010).

53. Hughes, J.P., Rees, S., Kalindjian, S.B. \& Philpott, KL. Principles of early drug Br. J. Pharmacol. 162, 1239-1249 (2011).

54. Swain, S.S., Paidesetty, S.K., Dehury, B.,......., Hussain, T. \& Padhy, RN. Molecular docking and simulation study for synthesis of alternative dapsone derivative as a newer anti- leprosy drug in multidrug therapy. Cell. Biochem. 119, 9838-9852 (2018).

\section{Tables}

Table 1. Docking scores (kcal/ mol) against SARS-CoV-2-Mpro (PDB ID: 6Y2E) and predicted drug-likeness, lethal doses $(\mathrm{kg} / \mathrm{mg})$ and bioavailability scores of individual anti- 
HIV drugs.

\begin{tabular}{|l|l|l|l|l|}
\hline $\begin{array}{l}\text { Anti-HIV protease } \\
\text { inhibitor drug }\end{array}$ & $\begin{array}{l}\text { Docking } \\
\text { score }\end{array}$ & $\begin{array}{l}\text { Drug } \\
\text { likeness }\end{array}$ & $\begin{array}{l}\text { Lethal } \\
\text { dose }\end{array}$ & $\begin{array}{l}\text { Bioavailability } \\
\text { score }\end{array}$ \\
\hline Amprenavir & -8.43 & 1.14 & 300 & 0.55 \\
\hline ASC09/TMC-310911 & -9.56 & 1.09 & 150 & 0.17 \\
\hline Atazanavir & -7.37 & 0.11 & 200 & 0.17 \\
\hline Darunavir & -10.25 & 0.60 & 245 & 0.55 \\
\hline Indinavir & -7.80 & 1.86 & 5000 & 0.55 \\
\hline Lopinavir & -9.00 & 1.10 & 5000 & 0.55 \\
\hline Nelfinavir & -9.97 & 1.41 & 600 & 0.55 \\
\hline Ritonavir & -8.75 & 0.11 & 1000 & 0.17 \\
\hline Saquinavir & -8.97 & 0.69 & 500 & 0.17 \\
\hline Tipranavir & -10.14 & 0.72 & 333 & 0.56 \\
\hline
\end{tabular}

Table 2. Docking scores (kcal/ mol) against SARS-CoV-2-Mpro (PDB ID: 6Y2E) and predicted drug-likeness, lethal doses $(\mathrm{kg} / \mathrm{mg})$ and bioavailability scores of individual phyto-flavonoids. 


\begin{tabular}{|l|l|l|l|l|}
\hline $\begin{array}{l}\text { Flavonoid class } \\
\text { phytochemical }\end{array}$ & $\begin{array}{l}\text { Docking } \\
\text { score }\end{array}$ & $\begin{array}{l}\text { Drug } \\
\text { likeness }\end{array}$ & $\begin{array}{l}\text { Lethal } \\
\text { dose }\end{array}$ & $\begin{array}{l}\text { Bioavailability } \\
\text { score }\end{array}$ \\
\hline Apigenin & -8.28 & 0.39 & 2500 & 0.55 \\
\hline Catechin & -8.86 & 0.64 & 10000 & 0.55 \\
\hline Dihydroquercetin & -7.98 & 0.50 & 159 & 0.55 \\
\hline Epigallocatechingallate & -7.69 & 0.23 & 1000 & 0.17 \\
\hline Hesperidin & -8.48 & 0.94 & 12000 & 0.17 \\
\hline Kaempferol & -7.91 & 0.50 & 3919 & 0.55 \\
\hline LPRP-Et-97543 & -10.11 & 0.82 & 2000 & 0.55 \\
\hline Quercetin & -8.33 & 0.52 & 159 & 0.55 \\
\hline Quercetin-3-rhamnoside & -10.90 & 0.82 & 2300 & 0.17 \\
\hline Rutin & -5.48 & 0.91 & 5000 & 0.17 \\
\hline
\end{tabular}

Table 3. Recorded interchanged double docking and ligand-ligand docking scores (kcal/ mol) against SARS-CoV-2-M ${ }^{\text {pro }}$ with selected anti-HIV drugs $(\mathrm{n}=2)$ and phyto-flavonoids $(\mathrm{n}=2)$.

\begin{tabular}{|l|l|l|l|l|}
\hline \multirow{2}{*}{ Docking types } & \multicolumn{3}{|c|}{ Double docking } & \multicolumn{2}{l|}{ Ligand-ligand docking } \\
\cline { 2 - 5 } & $\begin{array}{l}\text { SARS-CoV-2- } \\
\text { Flavonoids }\end{array}$ & SARS-CoV-2- & Darunavir & Tipranavir \\
& Mro-Darunavir & Mpro_Tipranavir & & \\
\hline Quercetin-3-rhamnoside & -10.95 & -10.84 & -3.88 & -3.34 \\
\hline LPRP-Et-97543 & -10.45 & -10.34 & -3.32 & -2.77 \\
\hline
\end{tabular}

Due to technical limitations, Tables 4-5 are provided in the Supplementary Files section.

\section{Figures}




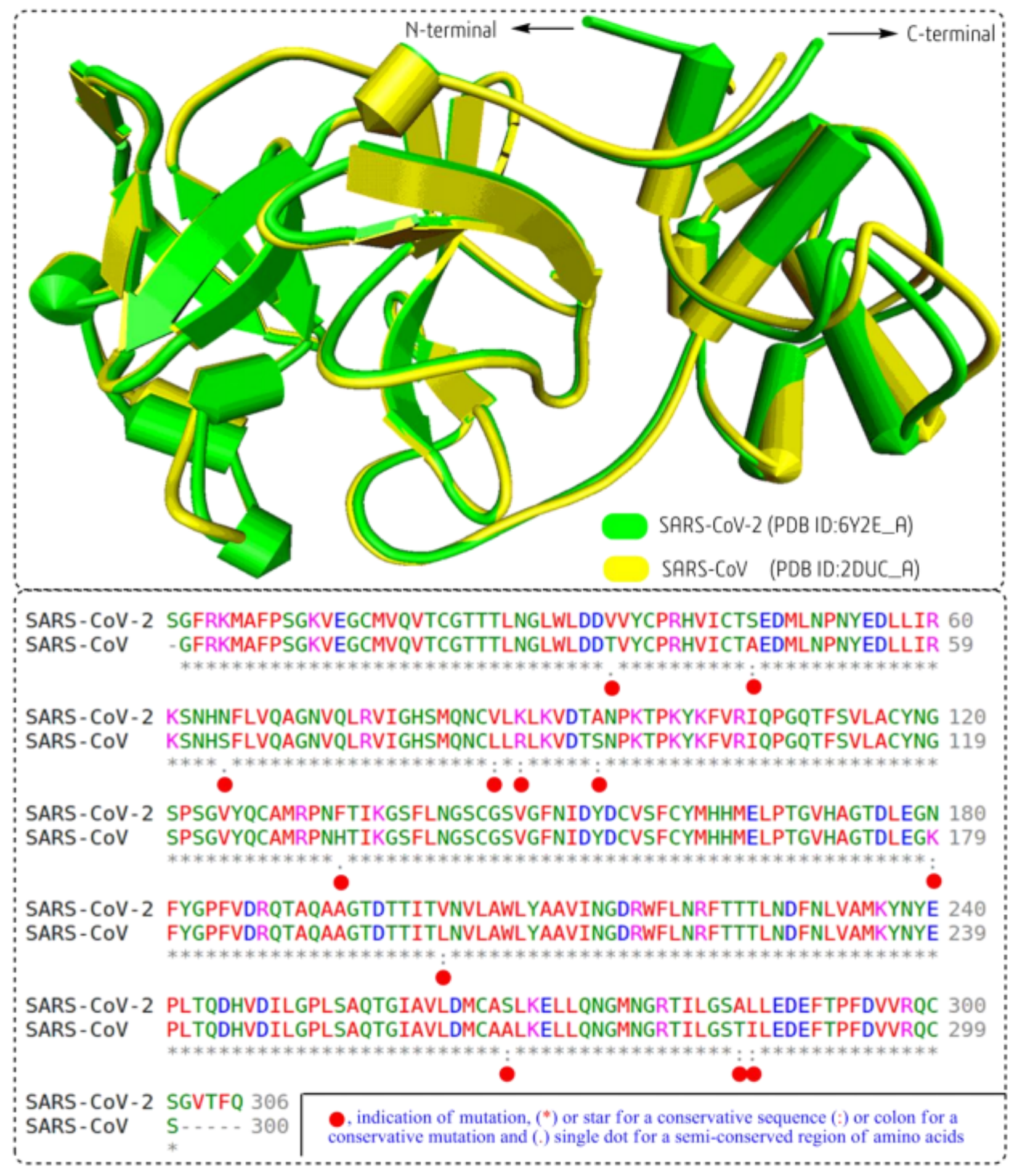

\section{Figure 1}

Protein structure superimpose and sequence analysis between SARS-CoV-2-Mpro (PDB ID: 6Y2E) with SARS-CoV-Mpro (PDB ID: 2DUC). 


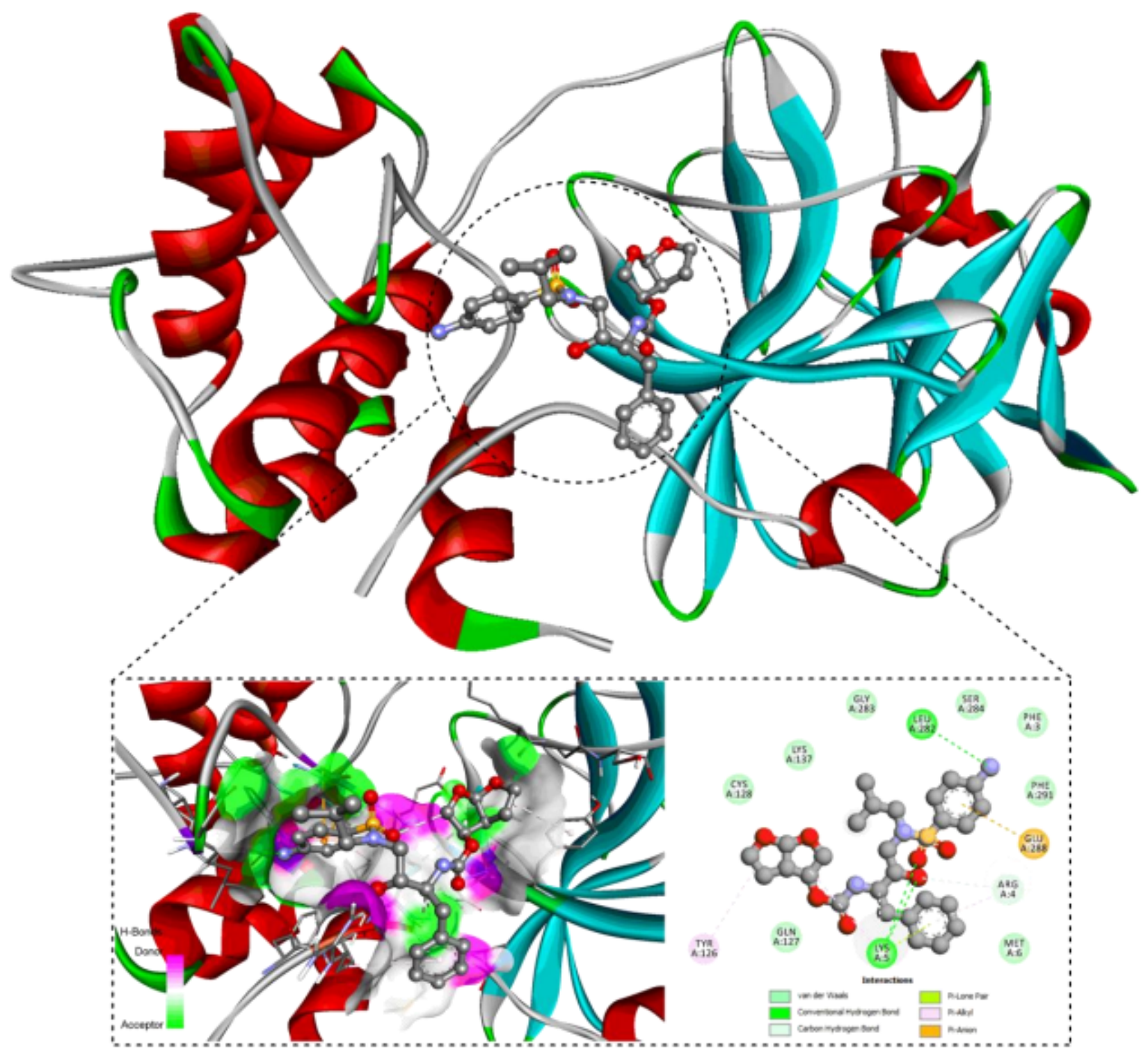

Figure 2

Molecular interactions of the potent anti-viral drug, darunavir against SARS-CoV-Mpro (PDB ID: 6Y2E) from docking study. The interactions image was visualized using BIOVIA DSV and interacted amino acids are highlighted in both $2 \mathrm{D}$ format. 


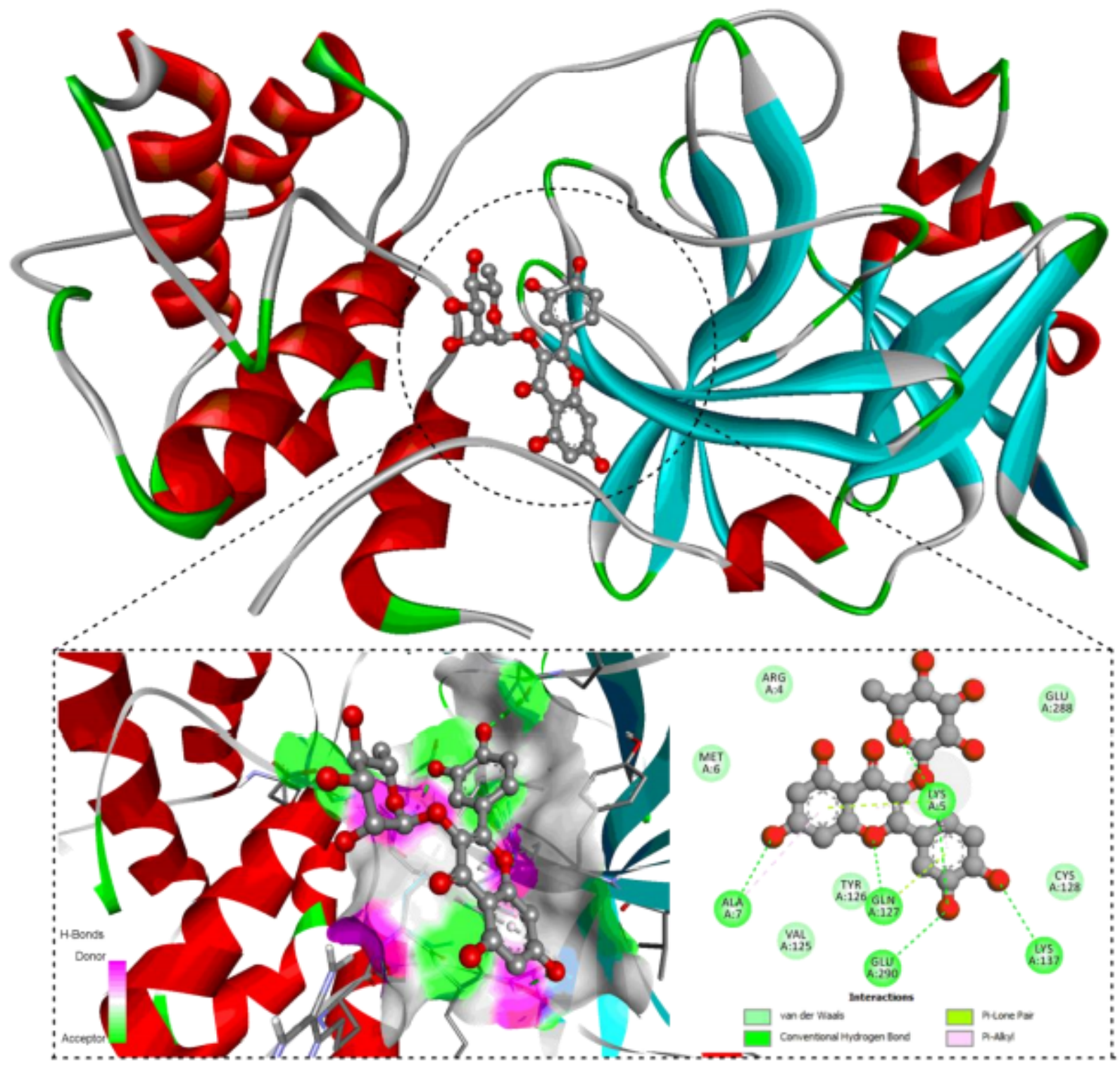

Figure 3

Molecular interactions of the potent phytochemical, quercetin-3-rhamnoside against SARS-CoV-Mpro from docking study. The interactions image was visualized using BIOVIA DSV and interacted amino acids are highlighted in both 2D format. 


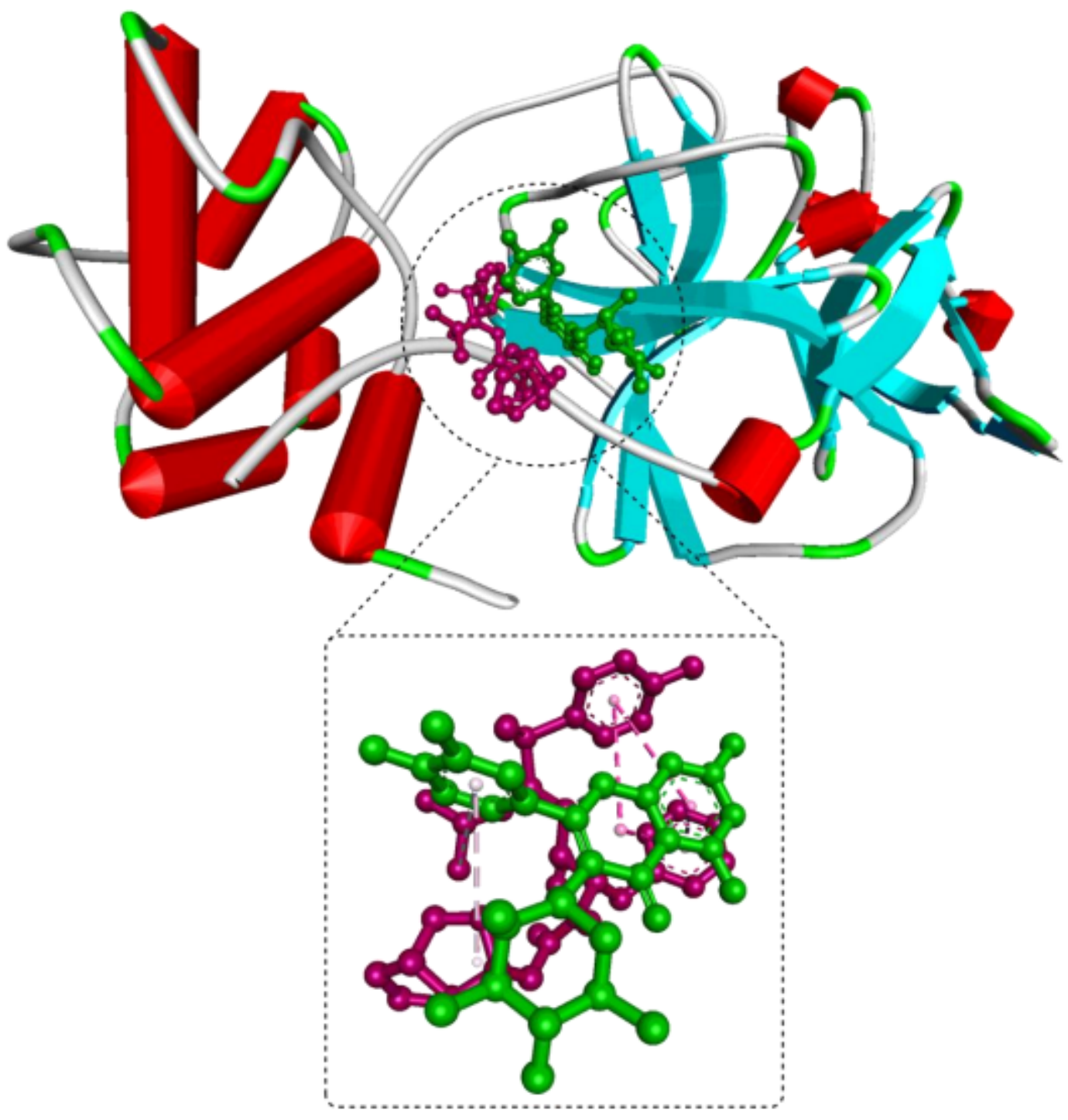

Figure 4

Molecular interactions of both the potent anti-viral drug, darunavir and the potent phytochemical, quercetin-3-rhamnoside phytochemical against SARS-CoV-Mpro, simultaneously from docking study. 


\section{RMSD}

Backbone after lsq fit to Backbone

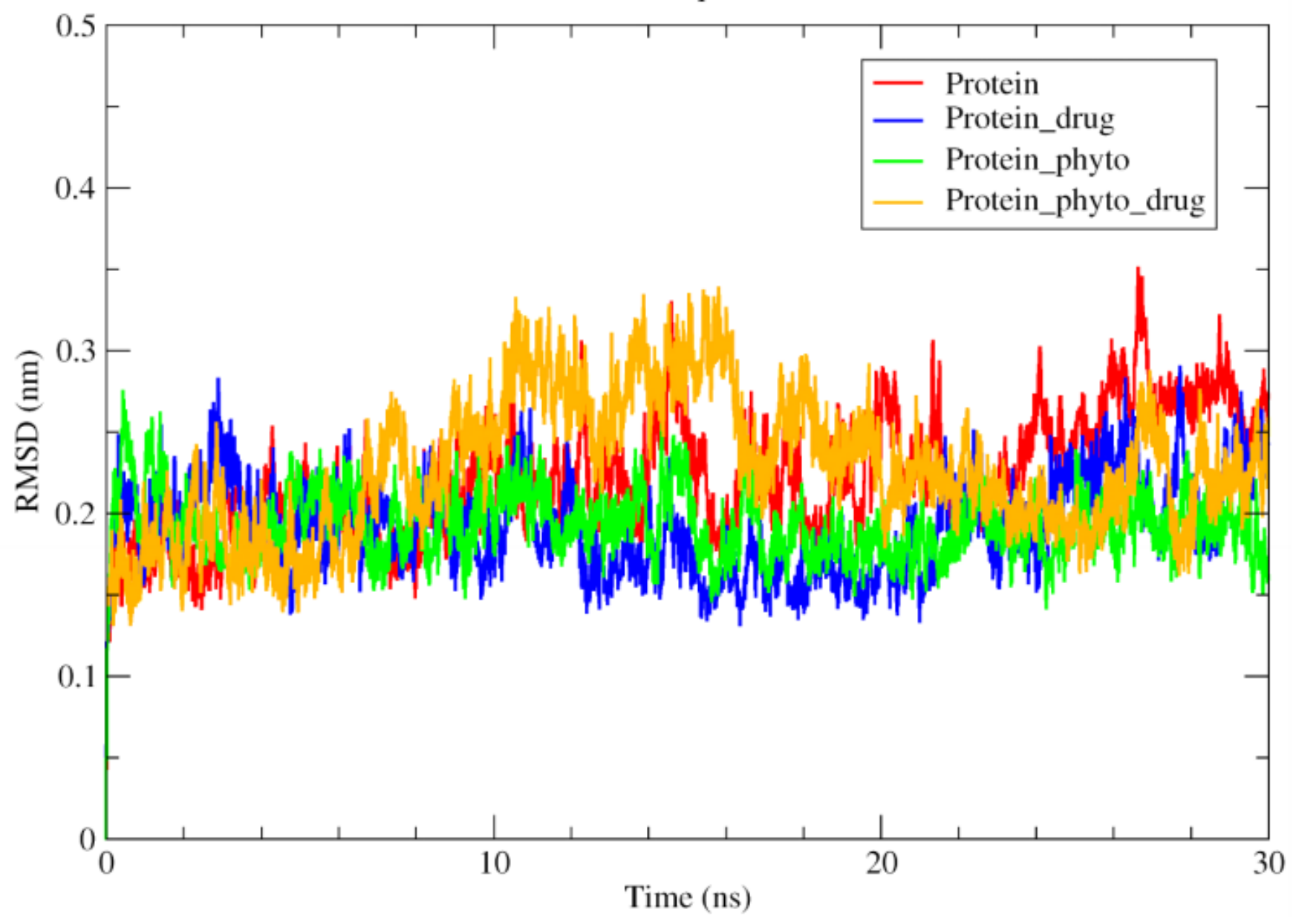

Figure 5

Analyzed RMSD-plots of 'protein', 'protein-drug', 'protein-phyto' and 'protein-drug- phyto' during conformational stability investigation at a $30 \mathrm{~ns}$ time. 


\section{RMS fluctuation}

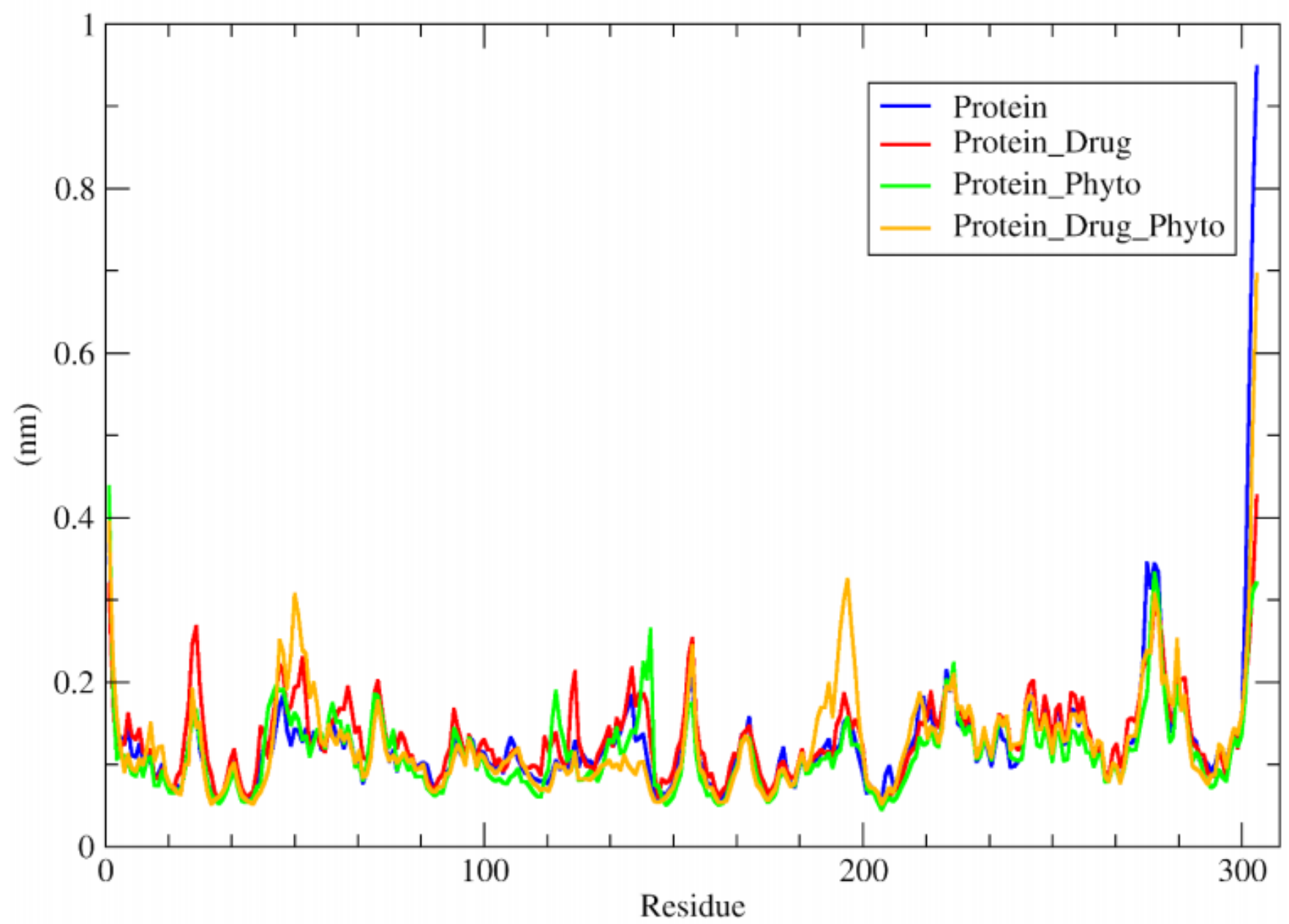

Figure 6

Analyzed RMSF-plots of 'protein', 'protein-drug', 'protein-phyto' and 'protein-drug- phyto' during conformational stability investigation at a $30 \mathrm{~ns}$ time. 


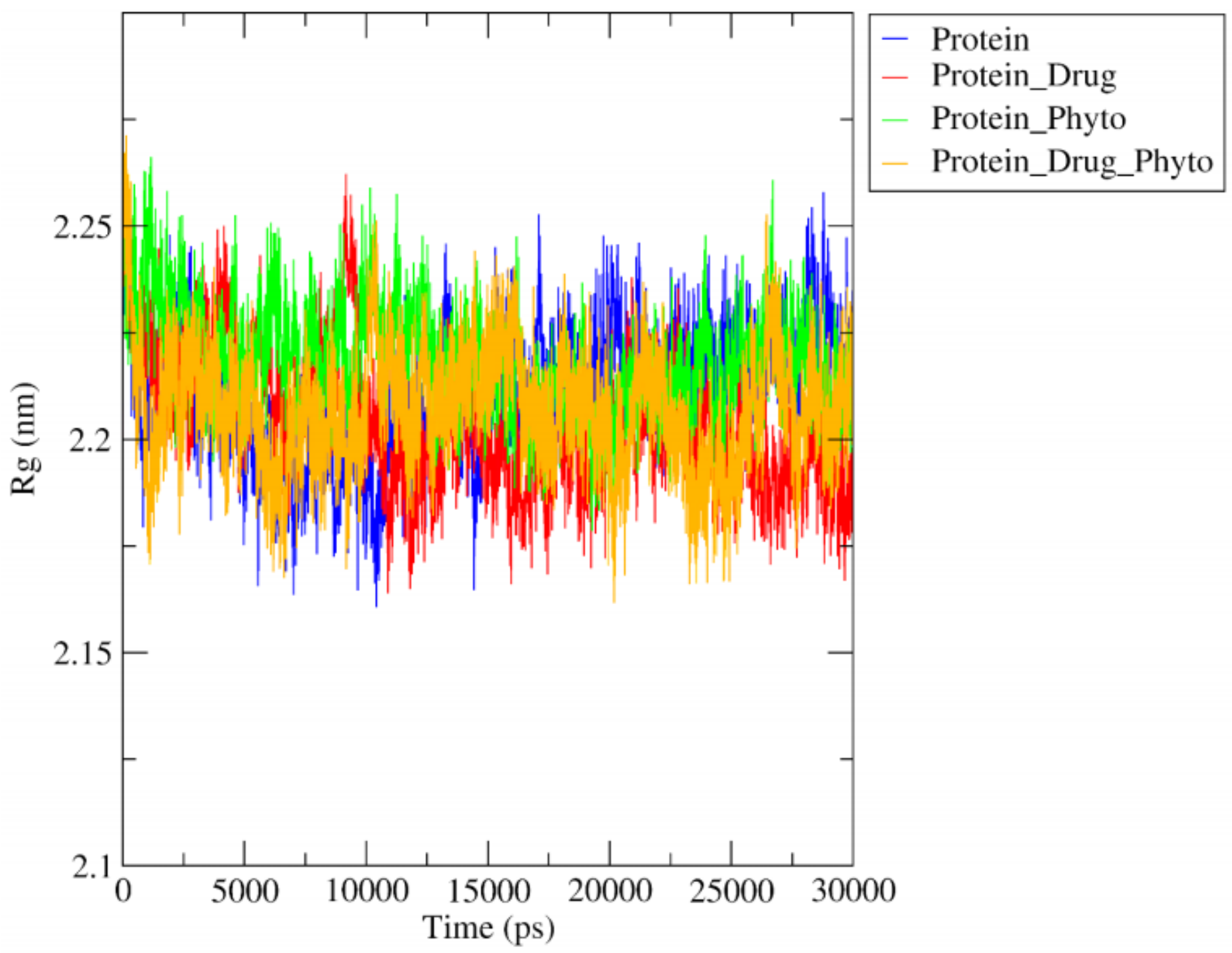

Figure 7

Analyzed Rg-plots of 'protein', 'protein-drug', 'protein-phyto' and 'protein-drug- phyto' during conformational stability investigation at a 30 ns time. 


\section{Hydrogen Bonds}

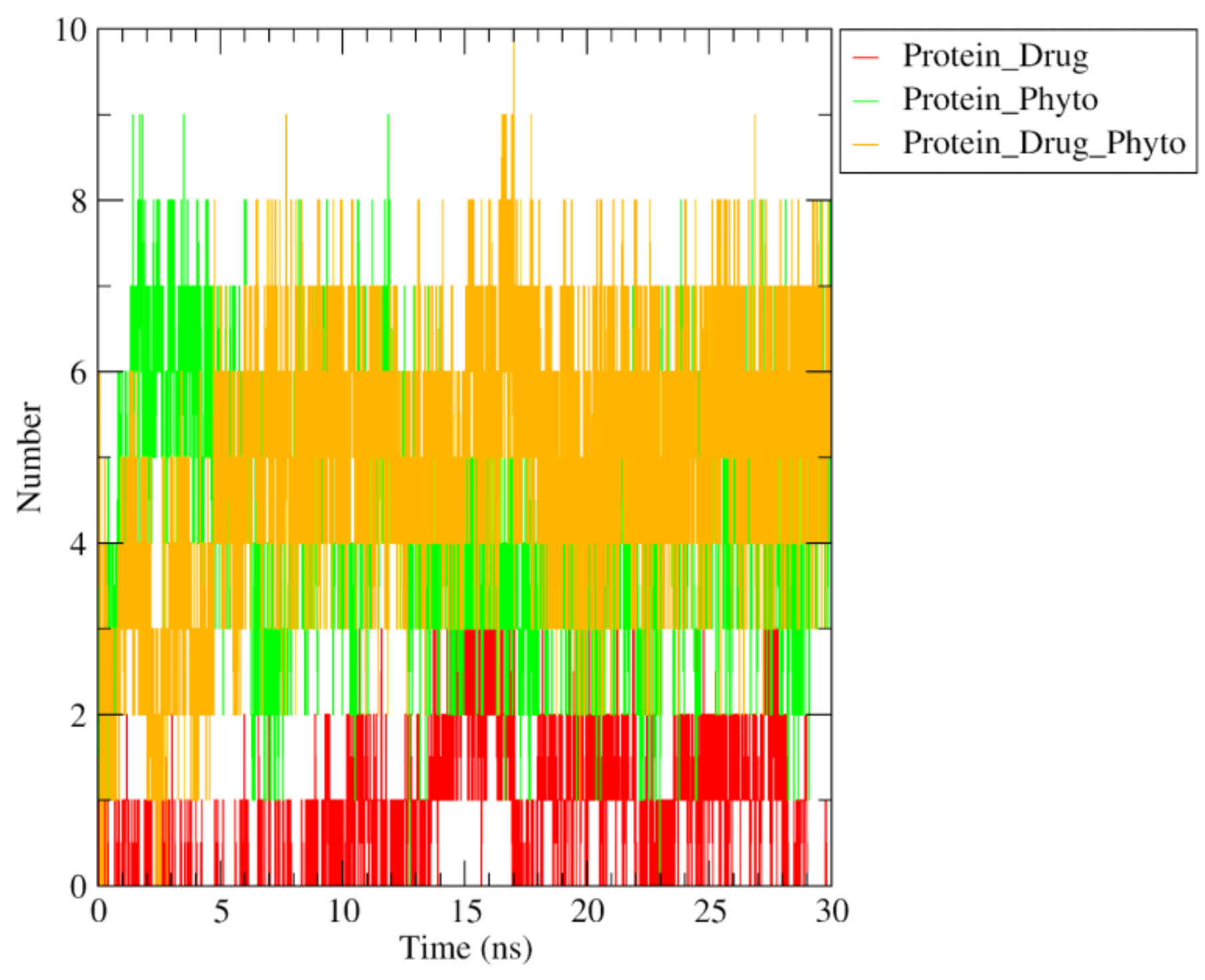

Figure 8

Analyzed hydrogen-bonds interactions plots of 'protein-drug', 'protein-phyto' and 'protein-drug-phyto' docking complexes after 30 ns.

\section{Supplementary Files}

This is a list of supplementary files associated with this preprint. Click to download.

- Supplementarydata.pdf

- Table45.docx 